\title{
LATRINE USE BY THE SHORT-BEAKED ECHIDNA TACHYGLOSSUS ACULEATUS
}

\author{
JenNifer A. Sprent, Niels A. ANDERSen ANd STEwart C. NicOl
}

IN mammals the basic functions of defaecation and urination have an inherent secondary function of chemical communication (Eisenberg 1981), and mammals have evolved a variety of behaviours based on these means of communication. Many mammals, particularly carnivores such as European badgers (Meles meles) (Stewart et al. 2002), honey badgers (Mellivora capensis) (Begg et al. 2003), and quolls (Dasyurus spp.) (Kruuk and Jarman 1995; Oakwood 2002), but also non-carnivorous species such as the rabbits (Sneddon 1991), leave accumulations of faeces, or latrines, that may serve a number of social functions, such as the marking of territories and the maintenance of dominance hierarchies.

In the course of radio-tracking short-beaked echidnas (Tachyglossus aculeatus) at our study site on a grazing property in the southern Tasmanian midlands we have discovered what are clearly echidna latrines. The approximately 1000 ha study area comprises a mixture of pasture and areas of remnant dry sclerophyll forest and woodland dissected by numerous gullies with sandstone outcrops, and contains about 100 resident echidnas. The majority of latrines were found under windrows piled up during land clearing activities, with one found under a single log lying amongst thick bracken. In a brief survey of part of the study area with cliffs and many rocky outcrops we found a latrine under a sandstone overhang. The presence of a latrine is indicated by an area of approximately $25 \mathrm{~cm}$ diameter which is clear of vegetation and sticks. Some sites have several (2-3) distinct latrines close together - less than $1 \mathrm{~m}$ apart - on the opposite sides or opposite ends of a log, but within the same $\log$ pile. Scats may be visible on the surface or buried several centimetres into the soil, which is soft and full of exoskeletons. Echidna scats consist mostly of soil, making them quite difficult to see; they can be neat cylinders up to around $5 \mathrm{~cm}$ long or simply resemble a pile of hardened soil. Upon close examination exoskeletons of ants and other chitinous prey items can be clearly seen. The soil-exoskeleton mix extends down around 5-10 $\mathrm{cm}$ and may contain crusty layers, probably caused by moisture - rain or urine - breaking down scats and the slurry then hardening as it dries. The latrines can have a strong 'echidna' odour and may be damp with rainwater or urine.

Of the 22 latrines discovered, four were found while tracking a single individual male (1E7C), as he was sheltering in the latrine or very close to it when located. Four more were located within his known home range. One latrine is within an area where we regularly find five animals, including $1 \mathrm{E} 7 \mathrm{C}$ and lies very close to the home ranges of another ten echidnas. Two other animals have been found within the area, one of which is known to have a home range $2 \mathrm{~km}$ distant.

In order to relate the amount of faeces to the number of defaecations, and thus the number of visits, we used the weight of what we judged to be a reasonably representative dry scat found next to a latrine as a standard scat. The ends of this scat were tapered and it appeared to be complete and weighed $46 \mathrm{~g}$. One latrine was cleared eight times between May 2002 and January 2005 yielding more than $1 \mathrm{~kg}$ of faeces in total which would represent a minimum of 20 repeated visits. Two sites, one of which had three distinct latrines within an area of $2 \mathrm{~m}^{2}$, and another with two latrines within an area of $1 \mathrm{~m}^{2}$, both yielded $2 \mathrm{~kg}$, representing more than 40 visits. Given the size of these deposits it is surprising that the only previous indications of the existence of echidna latrines are a brief comment by Griffiths (1968) that caves in Western Australia "contained pounds of echidna scats" and collections of scat samples from echidnas in the Northern Territory that contained up to 35 pieces (Griffiths et al. 1990).

Sprent JA, Andersen NA and Nicol SC, 2006. Latrine use by the short-beaked echidna Tachyglossus aculeatus. Australian Mammalogy 28: 131-133.

Key words: echidna, Tachyglossus aculeatus, latrine, home-range, behaviour, social structure.

JA Sprent, NA Andersen and SC Nicol, Anatomy and Physiology, University of Tasmania, Hobart, Tasmania 7001, Australia.Email: j_sprent@utas.edu.au. Manuscript received 30 January 2006; accepted 2 May 2006. 
Our first observation of a latrine was in 2002 and this latrine was still in use in 2005 . We checked seven of the latrines approximately every 30 days from September 2004 to January 2006, and found that they were continuously used between August and February. Between February and July Tasmanian echidnas hibernate (Nicol and Andersen 2002) and the latrines were not used during this period.

It is reasonable to assume that echidna latrines, like those of other mammals, have a social function. Burying faeces prolongs the period during which the odour remains strong (Eisenberg 1981), while their location gives them protection from weathering, particularly from rain, which rapidly breaks down echidna scats (Smith et al. 1989; Rismiller 1999). Scats are also deposited individually, with no association with latrines, and thus a key to understanding the role of latrines will be information on the circumstances in which echidnas use latrines, compared with when they do not.

Echidnas are considered to be solitary except during the breeding season (Augee et al. 1975; Griffiths 1978), although we have occasionally observed animals in close proximity to each other $(<1 \mathrm{~m})$ outside the breeding season (Andersen, Sprent and Nicol, unpubl. data). Echidnas have well defined home ranges that overlap significantly (Augee et al. 1975, 1992; Abensperg-Traun 1991; Wilkinson et al. 1998; Nicol and Andersen, unpubl. data), but there has been no previous evidence of any social structure in echidnas in the wild. Male dominance hierarchies may be important during echidna reproduction; during mating males may jostle each other for access to females and this behaviour has been observed in the field (Rismiller and McKelvey 2000), and in captivity (Brattsrom 1973; Boisvert and Grisham 1988).

Even solitary animals will have a social structure to maintain spacing and maximise resource utilization (Eisenberg 1981), and require an effective communication system to maintain their social organization and ensure reproductive success. Chemical or olfactory communication enables solitary animals to leave messages that are relatively long-lasting, can be 'read' later, and can also be used at night, underground or in dense vegetation (Begg et al. 2003). Olfactory communication clearly plays an important role in echidna mating behaviour, with males being attracted to females by scent (Rismiller 1992).

Begg et al. (2003) list a number of possible functions of scent marking in honey badgers which could also apply to echidna latrines: indicating the presence of dominant males, signalling of reproductive status by females, signalling home ranges and thus allowing spatio-temporal separation of neighbours, or signalling where an individual is feeding, thereby enabling individuals to partition resource use and increase foraging efficiency. These different hypothesised functions lead to specific predictions about patterns of use (Begg et al. 2003) which can be tested by field observations and knowledge of which animals are using the latrines. For example, a role in signalling reproductive status by females seems unlikely as latrine use is not confined to the mating period (early June to midSeptember, Nicol and Andersen in press) but occurs throughout the active period. Furthermore, in Tasmanian echidnas the female normally mates within one or two days of arousal from hibernation, (Nicol et al. 2005), sometimes before she has moved from her hibernaculum. In order to elucidate the role of these latrines, and gain insights into echidna social structure, we shall be continuing field studies, which will include the use of DNA analysis to indicate which animals are using latrines.

\section{ACKNOWLEDGEMENTS}

We thank Jutta Schmid for co-discovering the first latrine, and the McShane family for allowing us to undertake this continuing study on their property. This work was carried out under permit from the Tasmanian Department of Primary Industries, Water and Environment, and the University of Tasmania Animal Ethics Committee, and complies with the Tasmanian Animal Welfare Act (1993) and the Australian Code of Practice for the Care and Use of Animals for Scientific Purposes (2004).

\section{REFERENCES}

ABEnSPERG-Traun M, 1991. A study of home-range, movements and shelter use in adult and juvenile echidnas, Tachyglossus aculeatus (Monotremata: Tachyglossidae), in Western Australian wheat belt reserves. Australian Mammalogy 14: 13-22.

Augee ML, Beard LA and GrigG GC, 1992. Home range of echidnas in the Snowy Mountains. Pp. 225-231 in Platypus and echidnas ed by ML Augee. Royal Zoological Society of NSW: Mosman.

Augee ML, Ealey EHM AND Price IP, 1975. Movements of echidnas, Tachyglossus aculeatus, determined by marking-recapture and radiotracking. Australian Wildlife Research 2: 93-101.

Begg CM, Begg KS, Du Toit JT and Mills MGL, 2003. Scent-marking behaviour of the honey badger, Mellivora capensis (Mustelidae), in the southern Kalahari. Animal Behaviour 66: 917929. 
BOISVERT M AND GRISHAM J, 1988. Reproduction of the short-nosed echidna (Tachyglossus aculeatus) at the Oklahoma City Zoo. International Zoo Yearbook 27: 103-108.

BrattSROM B, 1973. Social and maintenance behavior of the echidna, Tachyglossus aculeatus. Journal of Mammalogy 54: 50-70.

EISENBERG JF, 1981. The mammalian radiations. University of Chicago Press: Chicago.

Griffiths M, 1968. Echidnas. Pergamon Press: Oxford.

GRIFFITHS M, 1978. The biology of monotremes. Academic Press Inc.: New York.

Griffiths M, Greenslade PJM, Miller L AND KERLE JA, 1990. The diet of the spiny-anteater Tachyglossus aculeatus acanthion in tropical habitats in the Northern Territory. The Beagle, Records of the Northern Territory Museum of Arts and Sciences. 7: 79-90.

KRUUK H AND JARMAN PJ, 1995. Latrine use by the spotted-tail quoll (Dasyurus maculatus: Dasyuridae, Marsupialia) in its natural habitat. Journal of Zoology 236: 345-349.

NicOL S AND ANDERSEN NA, 2002. The timing of hibernation in Tasmanian echidnas: why do they do it when they do? Comparative Biochemistry and Physiology. Part B, Biochemistry and Molecular Biology 131: 603-611.

Nicol SC AND ANDERSEN NA, in press. The life history of an egg-laying mammal, the echidna. Ecoscience.

Nicol SC, ANDERSEN NA AND JONES SM, 2005. Seasonal variations in reproductive hormones of free-ranging echidnas (Tachyglossus aculeatus): interaction between reproduction and hibernation. General and Comparative Endocrinology 144: 204-210.

OAKWOOD M, 2002. Spatial and social organisation of a carnivorous marsupial Dasyurus hallucatus (Marsupialia: Dasyuridae). Journal of Zoology, London. 257: 237-248.

RISMILLER PD, 1992. Field observations on Kangaroo Island echidnas (Tachyglossus aculeatus multiaculeatus) during the breeding season. Pp. 101-105 in Platypus and echidnas ed by ML Augee. Royal Zoological Society of NSW: Mosman.

RISMILlER PD, 1999. The echidna, Australia's enigma. Hugh Lauter Levin Associates Inc: Bridgeport Connecticut.
Rismiller PD AND MCKelvey MW, 2000 Frequency of breeding and recruitment in the short-beaked echidna, Tachyglossus aculeatus. Journal of Mammalogy 81: 1-17.

Smith AP, Wellham GS and GReen SW, 1989. Seasonal foraging activity and microhabitat selection by echidnas (Tachyglossus aculeatus) on the New England Tablelands. Australian Journal of Ecology 14: 457-468.

SNEDDON IA, 1991. Latrine use in the European rabbit (Oryctolagus cuniculus) Journal of Mammalogy. 72: 769-745.

Stewart PD, MacDonald DW, Newman C AND TATTERSALl FH, 2002. Behavioural mechanisms of information transmission and reception by badgers, Meles meles, at latrines. Animal Behaviour 63: 999-1007.

WILKINSON DA, GRIGG GC AND BEARD LA, 1998. Shelter selection and home range of echidnas, Tachyglossus aculeatus, in the highlands of south-east Queensland. Wildlife Research 25: 219-232. 
